\title{
Diabetes Mellitus Induces Hyperreactivity of 5-Hydroxytryptamine (5-HT)-Induced Constriction in Human Internal Thoracic Artery and Is Associated with Increase in the Membrane Protein Level of 5-HT ${ }_{2 \mathrm{~A}}$ Receptor
}

\author{
Tatsuo Shiba, ${ }^{a, \#}$ Atsuko Yokota, ${ }^{b, c, \#}$ Shuji Gamoh, ${ }^{a}$ Naoko Tanaka-Totoribe, ${ }^{a}$ \\ Masachika Kuwabara, ${ }^{d}$ Eisaku Nakamura, ${ }^{c}$ Takahiro Hayase, ${ }^{b}$ Kunihide Nakamura, ${ }^{c}$ and \\ Ryuichi Yamamoto*,a \\ ${ }^{a}$ First Department of Pharmacology, Graduate School of Clinical Pharmacy, Kyushu University of Health and \\ Welfare; Nobeoka, Miyazaki 882-8508, Japan: ${ }^{b}$ Department of Cardiovascular Surgery, Miyazaki Prefectural \\ Nobeoka Hospital; Nobeoka, Miyazaki 882-0835, Japan: ${ }^{c}$ Department of Surgery, Faculty of Medicine, Miyazaki \\ University; Miyazaki 889-1692, Japan: and ${ }^{d}$ Kuwabara Clinic; Miyazaki 882-8852, Japan. \\ Received December 12, 2017; accepted February 4, 2018; advance publication released online February 10, 2018
}

Studies indicate that 5-hydroxytryptamine (5-HT) released from activated platelets in coronary artery bypass grafting $(\mathrm{CABG})$ induces $5-\mathrm{HT}_{2 \mathrm{~A}}$ receptor-mediated graft spasm. We previously reported that 5-HTinduced constriction of human endothelium-denuded saphenous vein (SV) was significantly augmented in patients with diabetes mellitus (DM) than in patients without DM (non-DM), without changes in the levels of the membrane-bound 5- $\mathrm{HT}_{2 \mathrm{~A}}$ receptor of their smooth muscle cells. Although the internal thoracic artery (ITA) is the key graft conduit for CABG, the effect of DM on the ITA graft spasm is still unclear. Therefore, in this study, we investigated the effect of DM on 5-HT-induced vasoconstriction and the level of membranebound 5-HT ${ }_{2 \mathrm{~A}}$ receptor in ITA grafts. 5-HT-induced constriction of the isolated human endothelial-denuded ITA was significantly higher in patients with DM than in patients without DM. In addition, the level of the $5-\mathrm{HT}_{2 \mathrm{~A}}$ receptor in the membrane fraction of human ITA smooth muscle cells was significantly higher in patients with DM than in those without DM. These results demonstrate that DM is a risk factor for CABG in both venous and arterial conduits, and that it differentially affects the level of the membrane-bound 5-HT $\mathbf{2 A}_{2}$ receptor in the venous and arterial smooth muscle cells.

Key words 5-hydroxytryptamine; coronary artery bypass grafting; diabetes mellitus; internal thoracic artery; vasospasm

Reports show that diabetes mellitus (DM) increases shortterm mortality and morbidity in patients undergoing coronary artery bypass grafting (CABG). ${ }^{1)}$ One of the problems associated with $\mathrm{CABG}$ is that the bypass grafts undergo spasms after implantation into coronary arterial circulation. ${ }^{2,3)}$ Studies indicate that release of 5-hydroxytryptamine (5-HT) from activated platelets plays a crucial role in constriction of bypass grafts via activation of the $5-\mathrm{HT}_{2 \mathrm{~A}}$ receptor. ${ }^{4)}$

Endothelial dysfunction is consistently observed in patients with DM, which may induce vasoconstriction. ${ }^{5)}$ In contrast, several groups suggested that vascular hyperreactivity, caused by hyperglycemia, is mediated by changes in the expression of signaling molecules in vascular smooth muscle cells. ${ }^{6,7)}$ Therefore, mechanisms other than endothelial dysfunction may also participate in the vascular hyperreactivity. The saphenous vein (SV) has been commonly used as a conduit for CABG because of its ready availability and suppleness. ${ }^{8)}$ We previously reported that 5-HT-induced constriction was significantly augmented in human endothelium-denuded SV of patients with DM compared to those in patients without DM., ${ }^{9}$ ) Furthermore, we reported that the level of the $5-\mathrm{HT}_{2 \mathrm{~A}}$ receptor in the membrane fraction of human SV smooth muscle cells did not change between patients with and without DM. ${ }^{10}$

The internal thoracic artery (ITA) is the key graft conduit

\footnotetext{
${ }^{\#}$ These authors contributed equally to this work.

for CABG because of its excellent long-term patency. ${ }^{11,12)}$ However, the effect of DM on the arterial graft spasm is still unclear. Therefore, in this study, we investigated the effect of DM on 5-HT-induced constriction and the membrane level of $5-\mathrm{HT}_{2 \mathrm{~A}}$ receptor in ITA grafts.

\section{MATERIALS AND METHODS}

Preparation of Blood Vessels and Contractile Studies Human ITAs were obtained from patients undergoing CABG at the Miyazaki Prefectural Nobeoka Hospital (Nobeoka, Japan). ITA samples from 11 patients with DM (DM group) and 18 patients without DM (non-DM group) were used in this study. The diabetes status of patients was accepted as diagnosed from the medical records. At the Miyazaki Prefectural Hospital, portions of each ITA graft were sectioned for bypassing the occluded coronary arteries, whereas the remaining portion was used for experiments. The small ITA segments were transported and their constrictive responses were measured using the method followed for saphenous vein samples as described previously. ${ }^{9}$ )

Western Blot Analysis of the 5-HT $\mathbf{H A}_{\mathrm{A}}$ Receptor in the Membrane Fraction The endothelium-denuded ITA rings were flash frozen in liquid nitrogen and stored at $-80^{\circ} \mathrm{C}$ for Western blot analysis. Membrane fraction preparation and Western blot analysis were performed as described previous- 
ly. ${ }^{10)}$ Equal amounts of protein $(5.5 \mu \mathrm{g}$ per lane) were separated by sodium dodecyl sulfate (SDS)-polyacrylamide gel electrophoresis (PAGE) and transferred onto a Hybond-P polyvinylidene difluoride membrane (GE Healthcare, Japan, Tokyo, Japan). The membrane was blocked with $1 \%$ skim milk and reacted with rabbit anti-5- $\mathrm{HT}_{2 \mathrm{~A}}$ receptor $(1: 2000$, Santa Cruz Biotechnology, Dallas, TX, U.S.A., catalog No. sc-166775) or rabbit anti- $\beta$-actin $(1: 2000$, Cell Signaling Technology, Tokyo, Japan, catalog No. 3700 ) overnight at $4^{\circ} \mathrm{C}$. The immunoreactive bands were reacted with horseradish peroxidase-conjugated anti-rabbit antibodies, visualized using the Immuno-Star enhanced chemiluminescent detection system (Wako Pure Chemical Industries, Ltd., Osaka, Japan), and quantified using a luminoimage LAS-4000 analyzer (GE Healthcare, Japan). Protein levels of the $5-\mathrm{HT}_{2 \mathrm{~A}}$ receptor and $\mathrm{AT}_{1} \mathrm{R}$ were normalized to the $\beta$-actin levels. The amount of the ITA samples was limited because they were derived from the remnants left after the CABG operation. Since we prioritized the examination of constrictive reactivity, we could not perform Western blot analysis on the vascular samples from all patients.

Ethics Statement The ethics committees of the Miyazaki Prefectural Nobeoka Hospital and Kyushu University of Health and Welfare approved this study (acceptance numbers 09-004).

Statistical Analysis The number of subjects indicated in the figures is the number of patients. Differences between the baseline characteristics of patients, vasoconstriction, and membrane protein levels were analyzed using the chi-squared test, two-way ANOVA and Welch $t$-test. Data are presented as a mean \pm standard error of the mean (S.E.M.). Significance was assumed at $p<0.05$. Statistical analyses were performed using SPSS 21.0 J for Windows (IBM, Corp., Armonk, NY, U.S.A.).

\section{RESULTS}

The clinical characteristics of the patients in the two groups were almost well-matched (Table 1). The glycated hemoglobin A1c (HbA1c) level was significantly higher in the DM group than in the non-DM group.

First, we examined the 5-HT-induced constriction of isolated human endothelium-denuded ITAs. The cumulative administration of 5-HT $(1 \mathrm{nM}-10 \mu \mathrm{M})$ induced the constriction of the ITA in a concentration-dependent manner in both the DM group $(n=11)$ and the non-DM group $(n=18)$ (Fig. 1). Results of two-way ANOVA showed that the 5-HT-induced vasoconstriction was significantly higher in the DM group than in the non-DM group.

To investigate the reason underlying the significantly higher constrictive reactivity of ITA in the DM group, we determined the protein levels of the $5-\mathrm{HT}_{2 \mathrm{~A}}$ receptor in the membrane fraction prepared from ITAs harvested from patients with and without DM. Figure 2 shows the relative amounts of the $5-\mathrm{HT}_{2 \mathrm{~A}}$ receptor/ $\beta$-actin quantified using a bioimage analyzer. The $5-\mathrm{HT}_{2 \mathrm{~A}}$ receptor level in the membrane fraction was significantly higher in the DM group than in the non-DM group.

\section{DISCUSSION}

In this study, we included patients with DM who were receiving treatment for their condition. However, the HbAlc

Table 1. Clinical Characteristics of the DM Group and Non-DM Groups at Baseline

\begin{tabular}{|c|c|c|c|}
\hline \multirow{2}{*}{ Characteristics } & \multirow{2}{*}{$\begin{array}{c}\text { Non-DM group } \\
(n=18)\end{array}$} & \multirow{2}{*}{$\begin{array}{c}\text { DM group } \\
(n=11)\end{array}$} & \multirow{2}{*}{$p$-Value } \\
\hline & & & \\
\hline Age (years) & $68 \pm 2$ & $65 \pm 3$ & $\mathrm{~ns}$ \\
\hline Female sex $(\%)$ & $12(66.7)$ & $3(27.3)$ & ns \\
\hline $\mathrm{HbA}_{1 \mathrm{c}}(\%)$ & $5.1 \pm 0.1$ & $7.0 \pm 0.3$ & $<0.01$ \\
\hline \multicolumn{4}{|l|}{ Treatment for DM } \\
\hline Use of oral drugs $(\%)$ & & $11(100)$ & ns \\
\hline Use of insulin (\%) & & $2(18.2)$ & $\mathrm{ns}$ \\
\hline Body mass index $>26(\%)$ & $4(22.2)$ & $3(27.3)$ & ns \\
\hline Smoking (\%) & $12(66.7)$ & $5(45.5)$ & ns \\
\hline Hypertension (\%) & $15(83.3)$ & $10(90.9)$ & ns \\
\hline Hyperlipidemia (\%) & $12(66.7)$ & $10(90.9)$ & ns \\
\hline Chronic renal failure $(\%)$ & $3(16.7)$ & $2(18.2)$ & ns \\
\hline Chronic obstructive pulmonary disease $(\%)$ & $1(5.6)$ & $2(18.2)$ & $\mathrm{ns}$ \\
\hline Cerebrovascular accident $(\%)$ & $4(22.2)$ & $1(9.1)$ & ns \\
\hline Thoracic aortic aneurysm $(\%)$ & $2(11.1)$ & $0(0)$ & ns \\
\hline Peripheral arterial disease $(\%)$ & $4(22.2)$ & $1(9.1)$ & ns \\
\hline Previous myocardial infarction (\%) & $5(27.8)$ & $2(18.2)$ & ns \\
\hline \multicolumn{4}{|l|}{ Type of Angina } \\
\hline Stable $(\%)$ & $16(88.9)$ & $8(72.7)$ & ns \\
\hline Unstable (\%) & $2(11.1)$ & $3(27.3)$ & ns \\
\hline \multicolumn{4}{|l|}{ Coronary lesions } \\
\hline One-vessel disease (\%) & $2(11.1)$ & $1(9.1)$ & ns \\
\hline Two-vessel disease $(\%)$ & $9(50.0)$ & $1(9.1)$ & 0.0436 \\
\hline Three-vessel disease $(\%)$ & $8(44.4)$ & $8(72.7)$ & ns \\
\hline Left main disease $(\%)$ & $8(44.4)$ & $6(54.5)$ & ns \\
\hline Ejection fraction $(\%)$ & $55.9 \pm 2.3$ & $59.8 \pm 2.6$ & ns \\
\hline
\end{tabular}

Differences between the baseline characteristics of patients were analyzed using the chi-squared test for categorical data. 


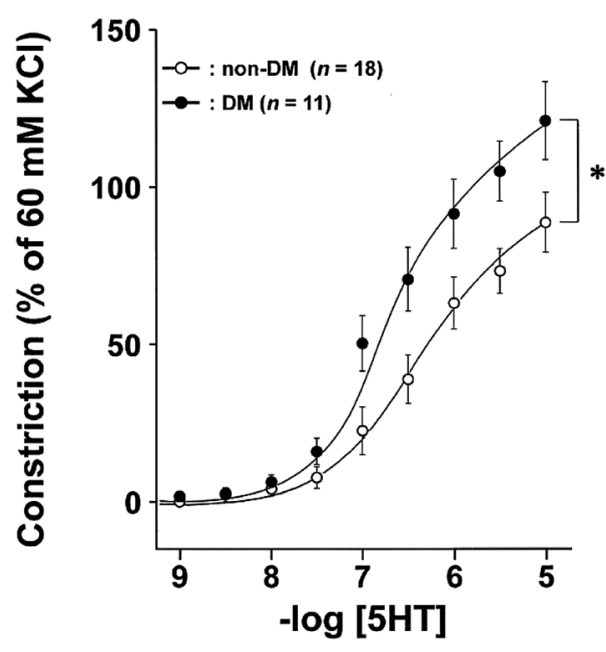

Fig. 1. The Contractile Reactivity to 5-Hydroxytryptamine (5-HT) of Endothelium-Denuded Internal Thoracic Arteries (ITAs) Harvested from Patients in the Non-DM (Open Circles, $n=18$ ) and DM Groups (Closed Circle, $n=11$ )

The vessel was cut into 2-mm rings, and the rings were denuded of endothelium by inserting an injection needle into the lumen and gently rolling the ring back and forth. Then, each rings were suspended between stainless steel hooks in a $5-\mathrm{mL}$ organ bath containing a modified Krebs buffer ( $\mathrm{pH}$ 7.4). One hook was connected to a force transducer to record the isometric tension. The ITA rings were stretched progressively to the optimal tension $(2.0 \mathrm{~g})$. After the tension of the rings had completely stabilized, they were preconstricted with $60 \mathrm{~mm} \mathrm{KCl}$. Thereafter, cumulative concentration-response curves to 5-HT for the concentration range of $1 \mathrm{~nm}-10 \mu \mathrm{M}$ were constructed. Finally, the contraction in response to a second exposure to $60 \mathrm{~mm} \mathrm{KCl}$ was recorded as the control contraction. The absolute forces of ITA rings induced by the second $60 \mathrm{~mm} \mathrm{KCl}$ in patients without and with DM were $1.09 \pm 0.15 \mathrm{~g}(n=18)$ and $1.19 \pm 0.19 \mathrm{~g}(n=11)$, respectively. The absolute forces of ITA rings induced by 5 -HT $(10 \mu \mathrm{M})$ in patients without and with DM were $0.84 \pm 0.12 \mathrm{~g}$ $(n=18)$ and $1.40 \pm 0.29 \mathrm{~g}(n=11)$, respectively. The contractile reactivity of ITA rings was evaluated considering the percentage of the second $\mathrm{KCl}$-induced vasoconstriction as $100 \%$. Data are expressed as a mean \pm S.E.M. Statistical comparisons of the mean value of 5-HT-induced vasoconstriction were made using two-way ANOVA. $* p<0.05$ compared to the non-DM group.
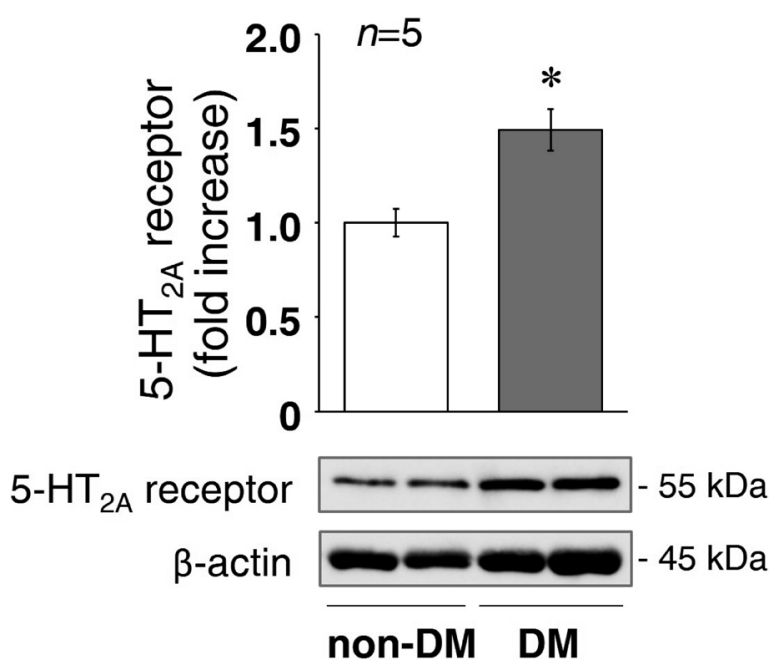

Fig. 2. Protein Levels of the $5-\mathrm{HT}_{2 \mathrm{~A}}$ Receptor Normalized to $\beta$-Actin Levels in the Membrane Fraction of Internal Thoracic Artery Smooth Muscle Harvested from Patients in the DM $(n=5)$ or Non-DM Groups $(n=5)$

Data are expressed as mean \pm S.E.M. Statistical comparisons of the $5-\mathrm{HT}_{2 \mathrm{~A}}$ receptor level in the membrane fraction of ITA smooth muscle cells were made using the Welch $t$-test. $* p<0.05$ compared to the non-DM group.

level was significantly higher in the DM group than in the non-DM group. We observed that 5-HT-induced constriction of the isolated human endothelial-denuded ITA was sig- nificantly higher in the DM group than in the non-DM group, which was consistent with the results of our previous study using isolated human endothelial-denuded SV. $\left.{ }^{9}, 10\right)$ The level of the $5-\mathrm{HT}_{2 \mathrm{~A}}$ receptor in the membrane fraction of human ITA smooth muscle cells was significantly higher in patients with DM than in patients without DM, which was different from the results of our previous study using isolated human endothelial-denuded SV. ${ }^{10}$ ) These results demonstrate that DM is a risk factor for CABG in both venous and arterial conduits. In addition, these results suggest that DM differentially affects the membrane level of the $5-\mathrm{HT}_{2 \mathrm{~A}}$ receptor in the venous and the arterial smooth muscle cells.

In our present study, we observed that the membrane level of the $5-\mathrm{HT}_{2 \mathrm{~A}}$ receptor in the ITA smooth muscle cells was significantly higher in the DM group than in the non-DM group. Thus, these results suggest that hyperreactivity to 5-HT in the ITA smooth muscle of patients with DM is because of increase in the membrane level of the $5-\mathrm{HT}_{2 \mathrm{~A}}$ receptor. In addition, these results are similar to our previous experimental results that in human endothelium-denuded SV, DM induces hyperreactivity of angiotensin II-induced constriction and is associated with increase in the membrane protein level of $\mathrm{AT}_{1}$ receptor. ${ }^{10)}$ In this experiment, the HbAlc level was significantly higher in the DM group than in the non-DM group. Thus, there is high possibility that before the CABG, ITA of patients without DM was exposed to higher concentration of insulin than ITA of patients with DM at least for 2-3 months. Since DM is associated with defects in insulin action, changes in physiological functions in patients with DM may be caused by insufficient insulin secretion. We previously reported that insulin receptor signaling via tyrosine kinase activation induces internalization of the plasma membrane $5-\mathrm{HT}_{2 \mathrm{~A}}$ receptor which was fused with yellow fluorescent protein for visualization and stably expressed in HEK293 cells. ${ }^{13)}$ Thus, it is likely that the increase in the membrane levels of the $5-\mathrm{HT}_{2 \mathrm{~A}}$ receptor in patients with $\mathrm{DM}$ is caused by impaired insulin-induced internalization of the plasma membrane-bound $5-\mathrm{HT}_{2 \mathrm{~A}}$ receptor. On the contrary, we recently reported that 5-HT-induced constrictive reactivity of isolated human endothelial-denuded $\mathrm{SV}$ in the DM group was higher compared to that in the nonDM group. ${ }^{9}$ (10) Interestingly, however, the membrane level of $5-\mathrm{HT}_{2 \mathrm{~A}}$ receptor was not affected by $\mathrm{DM}$ in the isolated human SV smooth muscle cells. ${ }^{10)}$ Further investigation is required to understand the mechanism underlying the differential effects of DM on the levels of the membrane-bound $5-\mathrm{HT}_{2 \mathrm{~A}}$ receptor in the SV and ITA smooth muscle cells.

We previously reported that the hyperreactivity to 5-HT in the SV smooth muscle of patients with DM is due to defective activity of myosin light chain phosphatase (MLCP). ${ }^{9)}$ Thus, the results can partially explain the poor patency of SV graft harvested from patients with DM. Further investigation is required to clarify the effect of DM on MLCP activity in ITA smooth muscle.

Acknowledgments This study was supported in part by JSPS KAKENHI Grant numbers JP25462154 and JP16K10646.

Conflict of Interest The authors declare no conflict of interest. 


\section{REFERENCES}

1) Carson JL, Scholz PM, Chen AY, Peterson ED, Gold J, Schneider SH. Diabetes mellitus increases short-term mortality and morbidity in patients undergoing coronary artery bypass graft surgery. $\mathrm{J}$. $\mathrm{Am}$. Coll. Cardiol., 40, 418-423 (2002).

2) Chanda J, Canver CC. Reversal of preexisting vasospasm in coronary-artery conduits. Ann. Thorac. Surg., 72, 476-480 (2001).

3) Fabricius AM, Gerber W, Hanke M, Garbade J, Autschbach R, Mohr FW. Early angiographic control of perioperative ischemia after coronary artery bypass grafting. Eur. J. Cardiothorac. Surg., 19, 853-858 (2001).

4) Gamoh S, Hisa H, Yamamoto R. 5-Hydroxytrypamine receptors as targets for drug therapies of vascular-related diseases. Biol. Pharm. Bull., 36, 1410-1415 (2013).

5) Eriksson L, Nyström T. Antidiabetic agents and endothelial dysfunction-beyond glucose control. Basic Clin. Pharmacol. Toxicol., 117, 15-25 (2015).

6) Wendler O, Landwehr P, Bandner-Risch D, Georg T, Schäfers HJ. Vasoreactivity of arterial grafts in the patients with diabetes mellitus: investigations on internal thoracic artery and radial artery conduits. Eur. J. Cardiothorac. Surg., 20, 305-311 (2001).

7) Ungvari Z, Pacher P, Kecskemeti V, Papp G, Szollár L, Koller A. Increased myogenic tone in skeletal muscle arterioles of diabetic rats. Possible role of increased activity of smooth muscle $\mathrm{Ca}^{2+}$ channels and protein kinase C. Cardiovasc. Res., 43, 1018-1028
(1999).

8) Lopes RD, Hafley GE, Allen KB, Ferguson TB, Peterson ED, Harrington RA, Mehta RH, Gibson CM, Mack MJ, Kouchoukos NT, Califf RM, Alexander JH. Endoscopic versus open vein-graft harvesting in coronary-artery bypass surgery. N. Engl. J. Med., 361, 235-244 (2009)

9) Matsuo Y, Kuwabara M, Tanaka-Totoribe N, Kanai T, Nakamura E, Gamoh S, Suzuki A, Asada Y, Hisa H, Yamamoto R. The defective protein levels of myosin light chain phosphatase (MLCP) in the isolated saphenous veins, as a vascular conduit in coronary artery bypass grafting (CABG), harvested from patients with diabetes mellitus (DM). Biochem. Biophys. Res. Commun., 412, 323-327 (2011).

10) Yokota A, Gamoh S, Tanaka-Totoribe N, Shiba T, Kuwabara M, Nakamura E, Hayase T, Hisa H, Nakamura K, Yamamoto R. Angiotensin II, as well as 5-hydroxytriptamine, is a potent vasospasm inducer of saphenous vein graft for coronary artery bypass grafting in patients with diabetes mellitus. Biochem. Biophys. Rep., 6, 82-87 (2016).

11) Del Campo C. Pedicled or skeletonized? A review of the internal thoracic artery graft. Tex. Heart Inst. J., 30, 170-175 (2003).

12) Tatoulis J. Total arterial coronary revascularization-patient selection, stenosis, conduits, targets. Ann. Cardiothorac. Surg., 2, 499506 (2013).

13) Ohkura M, Tanaka N, Kobayashi H, Wada A, Nakai J, Yamamoto R. Insulin induces internalization of the $5-\mathrm{HT}_{2 \mathrm{~A}}$ receptor expressed in HEK293 cells. Eur. J. Pharmacol., 518, 18-21 (2005). 